\title{
EL CONTRATO MÉDICO. CALIFICACIÓN, CONTENIDO Y RESPONSABILIDAD
}

\author{
THE MEDICAL CONTRACT. CLASSIFICATION, CONTENT AND \\ RESPONSIBILITY
}

\section{Carlos Pizarro Wilson ${ }^{*}$}

\begin{abstract}
RESUMEN: En este trabajo se aborda la calificación de la relación médico-paciente, su contenido y los efectos de su incumplimiento. Aquella debe entenderse como un contrato atípico, al que no cabe considerar un mandato, siendo su contenido contractual determinado por el legislador y el órgano administrativo competente, a través de las prácticas clínicas y protocolos reglamentados, lo que marca su carácter dirigido, a lo que se agrega la lex artis, modelada por lo que resulta esperable del profesional en las circunstancias en que se ejecuta el acto médico. Por último, se hace referencia a los efectos del incumplimiento, distinguiendo, en el ámbito médico, la responsabilidad por culpa de aquella objetiva, conforme se trate de una obligación de medios o de resultado.
\end{abstract}

Palabras clave: Responsabilidad médica, contrato dirigido, lex artis, obligaciones de medio y de resultado.

ABSTRACT: This work addresses the classification and content of the doctor-patient relationship as well as the effects of non-compliance. The contract is regarded as atypical and cannot be considered a mandate, being that its contractual content is determined by the legislature and the competent administrative body, through clinical practices and regulated protocols that mark its directed character. To this we add the lex artis, which is shaped by what is expected of the professional in the circumstances in which the medical act is carried out. Finally, the work addresses the effects of non-compliance, distinguishing, in the medical environment, the responsibility by fault of that objective, as it is an obligation of means or result.

Key words: Medical liability, directed contract, lex artis, obligations of means and results.

\section{INTRODUCCIÓN}

La responsabilidad civil médica ha padecido en los últimos años una inflación normativa y jurisprudencial considerable. Un verdadero mosaico de leyes e interpretaciones jurisprudenciales construyen el edificio actual de la responsabilidad por negligencias médicas $^{1}$. A partir del derecho común previsto en el Código Civil, donde conviven, conforme exista o no contrato, el estatuto contractual o extracontractual ${ }^{2}$, y en las hipótesis en que

\footnotetext{
" Profesor Investigador Facultad de Derecho de la Universidad Diego Portales, Santiago, Chile. Doctor en derecho Universidad Paris II (Panthéon-Assas), Correspondencia a: Correo electrónico carlos.pizarro@udp.cl. Este trabajo forma parte del Proyecto Regular Fondecyt no 1130171.

${ }^{1}$ Barros (2006) pp. 656 y ss., Pizarro (2008a) p. 539.

2 Corral (2003) pp. 273 y ss., Tapia (2003) pp. 75 y ss.
} 
se estima aplicable el régimen del contrato, es importante considerar el debate acerca de la recepción e implicancias de las obligaciones de medio y de resultado ${ }^{3}$. En el ámbito de los servicios de salud, debe tomarse en cuenta la Ley 19.966 de $2004^{4}$, más conocida como "Ley Auge", cuyo articulado conforma un régimen particular para la indemnización de daños ocasionados por falta de servicio de los órganos públicos de salud ${ }^{5}$. Todavía, para determinadas hipótesis -hospitales militares-, resulta inaplicable la Ley 19.966 de 2004, siendo pertinente el Código Civil: una vuelta al derecho común. Otros problemas particulares atañen a las infecciones intrahospitalarias ${ }^{6}$, la responsabilidad por el hecho ajeno ${ }^{7}$ y aquella del equipo profesional ${ }^{8}$. En fin, es posible interrogarse sobre la implicancia de la Ley 19.946 de 1996, cuyo empuje cada día extiende más su ámbito normativo9. Más aún si la Corte Suprema, en dos sentencias ha hecho aplicable la ley del consumidor a problemas atingentes a la calidad de la prestación ${ }^{10}$.

Este conjunto de leyes, el Código Civil, la Ley 19.996 de 2004 y la Ley 19.496 de 1996, confluyen, en la práctica, para dar respuesta a los daños ocasionados a propósito de negligencias médicas.

Por su parte, la jurisprudencia muestra las mismas vicisitudes que, en general, observamos en la propia responsabilidad civil. Una pérdida paulatina de presencia del Código Civil como régimen común. Languidece la ley civil ante la irrupción de leyes especiales, en un franco proceso de descodificación, dando lugar a una miríada de reglas.

Este fenómeno, cuya irrupción aparece durante el siglo XX, revela la insuficiencia de la ley común para resolver los problemas contemporáneos en el ámbito del derecho de daños, exigiendo al legislador respuestas, aunque no siempre sean oportunas o efectivas ${ }^{11}$. Ya no es suficiente la adecuación por vía interpretativa, ni tampoco la función pretoriana de los jueces, se hace necesaria una nueva ley. Es este fenómeno lo que explica la Ley

\footnotetext{
${ }^{3}$ Domínguez Hidalgo (2010) pp. 21 y ss., Cárdenas (2010a) pp. 45 y ss. Un reciente fallo acepta la clasificación, pero lo distintivo es que admite de manera explícita las obligaciones de resultado de los médicos, Treizman con Reyes (2013).

${ }^{4}$ Pizarro (2007) pp. 401 y ss., Pizarro (2010), pp. 187 y ss., Cárdenas (2010b) pp. 527 y ss., Cárdenas (2011).

5 Un análisis jurisprudencial acerca de la falta de servicio en Cárdenas y Mollinet (2011) pp. 47 y ss.

${ }^{6}$ Véase Tocornal (2010) pp. 477 y ss.

7 Pizarro (2003) pp. 181 y ss.

8 Pizarro (2011) pp. 668 y ss.

9 En particular sobre el ámbito de aplicación de la Ley 19.496 de 1996 debe considerarse el artículo 2 letra f), cuyo texto es: "Los actos celebrados o ejecutados con ocasión de la contratación de servicios en el ámbito de la salud, con exclusión de las prestaciones de salud; de las materias relativas a la calidad de estas y su financiamiento a través de fondos o seguros de salud; de la acreditación y certificación de los prestadores, sean estos públicos o privados, individuales o institucionales y, en general, de cualquiera otra materia que se encuentre regulada en leyes especiales". Véase Momberg (2013) pp. 75 y ss.

10 Gaete con Integramédica (2007). Se rechazó recurso de queja interpuesto por el centro privado de salud, senalándose que la materia debatida se circunscribe a la calidad de la prestación médica. En otra sentencia de la Corte Suprema se acoge un recurso de queja, liberando de responsabilidad a la clínica, lo que llevaría a concluir de manera oblicua en la ratificación de competencia de los juzgados de policía local para conocer de asuntos relativos a la prestación de salud. Sin embargo, este asunto, la competencia, no fue materia del recurso de queja, por lo que no parece conclusivo el fallo a ese respecto. Cfr. Momberg (2013) p. 76.

11 En relación a este proceso, véase GuZMÁn et al. (2005), en particular, pp. 27 y ss.
} 
no 20.584 de 2012 que regula "los derechos y deberes que tienen las personas en relación con acciones vinculadas a su atención de salud”, publicada el 24 de abril de 2012. La ley, discutida por largo tiempo en el parlamento, ratifica que en el Código Civil no hay una regulación comprensiva de los derechos de los pacientes en forma sistemática y adecuada a la concepción actual de la persona ${ }^{12}$. Establecer derechos de la persona o la teoría de los derechos de la personalidad es ajena al derecho civil codificado. Si bien algunos códigos modernos los han integrado, nuestro Código Civil sigue anclado en una concepción de propiedad sin considerar a la persona. Esta insuficiencia justifica una ley de estas características.

Todos estos aspectos, tanto la evolución doctrinal y jurisprudencial y la descodificación, vienen a complementarse con la entrada en vigencia de la ley que regula los derechos y deberes que tienen las personas en relación con acciones vinculadas a su atención de salud, ya citada, lo que transforma la relación médico paciente en un verdadero contrato dirigido, cuyo contenido quedó modelado en gran medida por el legislador ${ }^{13}$.

Esta nueva normativa repercute en el contenido del contrato médico ${ }^{14}$. Tiene implicancias en relación a la obligación de seguridad, que deben prodigarle los médicos a los pacientes y ensancha los deberes tipificados de los médicos. En lo que sigue, intentaré corroborar esta tesis. Para lograrlo, me referiré a la configuración de la relación médico-paciente. Descartaré los prestadores institucionales de salud, concentrándome en el contrato médico entre un profesional de la salud y el paciente. Determinada la calificación del contrato, aludiré a su contenido, plasmado en directrices otorgadas por el propio legislador o el órgano administrativo competente, sumado a la lex artis como parámetro general de conducta exigible al médico. A su turno, dicho contenido, para clarificar el régimen de responsabilidad, debe descifrarse si corresponde a una obligación de medios o de resultado. Esto definirá el tipo de responsabilidad que le es aplicable al médico.

\section{LA RELACIÓN MÉDICO-PACIENTE: UN CONTRATO ATÍPICO}

Diversas vicisitudes han marcado la definición y caracteres del contrato médico ${ }^{15}$. La calificación contractual, aplicable a la relación que une al paciente con el médico, se ha instalado desde hace tiempo en la doctrina nacional. Se asume ese vínculo entre el médico y el paciente como un genuino contrato. De manera imperceptible se anuda esa relación contractual, ya sea por la mera llamada telefónica para concertar la cita o, menos frecuente, por la llegada a la consulta. O, incluso, si el paciente contacta con el médico a través de la clínica, también concurrirá un vínculo contractual con el facultativo médico. No es necesario recurrir a la idea de estipulación a favor de otro para aceptar dicha calificación. Se generan obligaciones recíprocas entre el médico y el paciente, aunque haya sido generado el vínculo a través de la clínica, sin perjuicio de la responsabilidad de esta por sus propias obligacio-

12 Un análisis precedente a la ley que considera el proyecto, FigueroA (2010) p. 199.

13 Acerca del contrato dirigido en Chile, el clásico artículo Alessandri (1940) pp. 5 y ss. y López (2010) p. 137.

14 Acerca de la integración del contrato, en términos generales, véase Domínguez Hidalgo (2011) pp. 251 y ss.

15 Domínguez Hidalgo (2006) pp. 138 y ss.; también Mantilla (2008) p. 483. 
nes relativas a infraestructura o de hotelería y aquellas por el hecho del médico, si estuviere comprendida en su prestación de servicios.

En todos esos casos existe un acuerdo de voluntades a partir del cual se generan obligaciones para ambas partes. Salvo excepciones, inconsciencia de la víctima al ingreso del recinto hospitalario o de la clínica, la regla general es el vínculo contractual ${ }^{16}$. Asumiendo que se trata de un contrato, cierta doctrina y jurisprudencia ha planteado que deberíamos construir su régimen legal conforme a las reglas del mandato, según lo dispuesto en el artículo 2118 del Código Civil ${ }^{17}$. Se ha sostenido que ese precepto haría extensible todo el régimen del mandato al contrato de prestación de servicios médicos. Mientras el médico sería el mandatario, el paciente sería el mandante, que por su cuenta y riesgo encarga uno o más negocios al primero. A partir de esta premisa, concluyó Alessandri, el médico agravaría su diligencia en los términos previstos en el artículo 2129 del Código Civil, por tratarse de un mandato remunerado y a este le correspondería probar, también, la diligencia, conforme el artículo 1547 inciso $3^{\circ}$ del mismo Código. En el mismo sentido, Barros Bourie afirma que "Se trata típicamente de contratos a los que resultan aplicables las reglas del mandato (artículo 2118) y supletoriamente las del arrendamiento de servicios inmateriales (artículo 2012) ${ }^{18}$. Y para la perfección del contrato, entiende que será usual la aceptación tácita, de acuerdo al artículo 2124, inciso 20 del Código Civil”"

Esta posición ha sido criticada con acierto $^{20}$, pues lejos de configurarse un encargo por cuenta y riesgo del mandante, concurre una genuina prestación de servicios. No parece adecuado entender que el médico realiza actos o negocios jurídicos por cuenta del paciente. El facultativo médico ejecuta prestaciones de índole médica que podemos calificar como obligaciones de hacer, lo que permite otorgarle la calificación, más bien, de contrato de servicios, en este caso, servicios médicos ${ }^{21}$.

El autor Stitchkin, a propósito de esta regla, manifestó que no existe una calificación jurídica de esos servicios, sino que solo se limitó a decir que se sujetan a las reglas del mandato. Lo que corrobora, aludiendo a que esas mismas relaciones jurídicas quedan sometidas al contrato de arrendamiento de servicios inmateriales. Luego señaló que "De manera, entonces, que no podemos decir que en nuestro derecho se califiquen de mandato, no obstante aplicárseles principalmente las reglas de este contrato" ${ }^{22}$. Por lo mismo, Stitchkin concluye que "Si la prestación de estos servicios no consiste en la gestión de uno o más negocios, el contrato será de arrendamiento de servicios inmateriales (como el médico que

\footnotetext{
16 Alessandri (1942) p. 75; Barros (2006) p. 657, quien manifiesta lo impropio de la distinción en el ámbito médico; en el mismo sentido, antes, TAPIA (2003) p. 75.

17 Alessandri (1942) p. 75. El autor en forma expresa señala que: "Los servicios de estos profesionales se sujetan a las reglas del mandato (art. 2118) y a las que rigen el arrendamiento de servicios inmateriales, en lo que no fueren contrarias a aquellas (art. 2012). La misma idea en DE LA MAZA (1989) pp. 7 y ss.

${ }_{18}$ Es usual citar la sentencia relativa a un odontólogo en que la Corte de San Miguel califica la relación médico-paciente como mandato, Saccan con Ortega (1992). Nótese que en este caso el desempeño del profesional tuvo lugar en un establecimiento público de salud, lo que hace más discutible la calificación.

19 Barros (2006) p. 657.

${ }^{20}$ Mantilla (2008) pp. 485 y 486.

${ }_{21}$ Mantilla (2008) p. 486.

${ }^{22}$ Stitchkin (1975) p. 75.
} 
atiende la consulta o el abogado que informa en derecho)"23. Aun compartiendo la posición del profesor Stitchkin, en relación a que no estamos frente a un mandato en la hipótesis del contrato médico, eso no resuelve que el artículo 2118 del Código Civil haría aplicable, en lo que fuere pertinente, las normas de dicho contrato. Sin embargo, siguiendo a Mantilla, creemos que esa posición es errada. En la hipótesis que el objeto del contrato sean actos materiales, es ineludible calificar el contrato como arrendamiento de servicios inmateriales, quedando relegado el mandato al caso en que la prestación consista en el encargo de uno o más negocios por cuenta del mandante. No concurriendo, en ningún caso, este objeto, tratándose del contrato médico, es inapropiado aplicarle las reglas del mandato.

Además, la explicación histórica del citado artículo 2118 del Código Civil esclarece su sentido en razón del origen gratuito y honorífico del mandato ${ }^{24}$. Aun debiera considerarse para excluir la calificación de mandato que este contrato comprende una relación de confianza cada vez más ajena a la relación médico-paciente, si consideramos el incremento de servicios médicos cuya prestación se enmarca en un establecimiento privado -clínica- o público -servicio de salud-. Este vínculo complejo entre el médico y el paciente o entre el prestador público o privado y el paciente, se nutre de diversas obligaciones y derechos. La relación médico-paciente consiste en un contrato atípico, en el sentido que no aparece su régimen legal descrito en forma orgánica y sistemática en la ley. Las reglas especiales relativas al arrendamiento de servicios inmateriales, en que predomina la inteligencia sobre la mano de obra, no se adaptan, tampoco, al servicio que prestan los médicos. Esas reglas, al analizarlas, refieren a obras artísticas, en general, actores, educadores de latín, niñeras o ayas y cantores. Alude al término de la relación por cualquiera de las partes (artículo 2009 del Código Civil), el cambio de residencia y sus efectos (artículo 2010 del Código Civil) y al retiro intempestivo (2011 del Código Civil). Sin perjuicio que conforme al artículo 2006 del Código Civil le resultan aplicables los artículos 1997, 1998, 1999 y 2002, todos del Código Civil, que relativos a las obras materiales, norman el precio del servicio, perjuicios por incumplimiento y la alternativa entre el cumplimiento forzado y la indemnización a favor del artífice. Como puede observarse, resulta difícil que esas normas, que edifican el régimen legal del contrato de arrendamiento de servicios inmateriales sea útil para regular la relación entre el médico y el paciente.

De ahí que debamos rendirnos a la evidencia que la relación entre el médico y el paciente consiste en un genuino contrato atípico y complejo. Atípico en el sentido que no aparece su régimen legal descrito en forma sistemática por el legislador. Complejo, bajo el prisma que confluyen en su contenido un conjunto de obligaciones y derechos, cuyo origen se encuentra en las prácticas, la lex artis y en forma dispersa por la voluntad del legislador. Si bien la calificación de contrato de prestación de servicios de índole médicas no es inexacta, no aporta para esclarecer el contenido, pues como ya se dijo, lo que expresa el Código Civil no se adapta en nada a la relación entre el médico y el paciente. De ahí que sea pertinente hablar de contrato complejo, en que si bien algo puede aportar el tipo de contrato de arrendamiento de servicios, en lo que no sea pertinente o en lo que guarde silencio, deberá

23 STITCHKIN (1975) p. 75.

24 Mantilla (2008) pp. 487 y 488; Levi y Castaldo (2002) pp. 701 y ss. 
construirse el contenido mediante la interpretación objetiva del contrato, considerando lo ya indicado a propósito de la lex artis, las prácticas clínicas y lo dicho por el legislador.

El conjunto de actos que involucra la prestación médica amerita la categoría de contrato complejo. La naturaleza variada de actos sucesivos y coetáneos en el tiempo ha significado que ciertos autores otorguen el calificativo a la relación médico-paciente como contrato marco y de aplicación o a una "sucesión de contratos" 25 . Si bien puede resultar seductora la idea de diagramar la relación médico-paciente como un contrato marco o una sucesión de contratos particulares, es más apropiado entender que dicho contrato es simplemente atípico, y que si bien queda sometido a la teoría general del contrato, en lo que le fuere pertinente, lo importante consiste en establecer su contenido. Ahí encontraremos el régimen legal que le resulta aplicable, siendo necesario construir ese contenido contractual que es obligatorio. Es cierto que en determinadas oportunidades y en relación a ciertas obligaciones propias a la relación médico-paciente, el derecho de los contratos no resulta aplica$b^{26}$. Pero ese planteamiento no debe significar excluir su calificación de contrato. En no pocas ocasiones relaciones jurídicas que entendemos son contratos no le resultan aplicables determinadas instituciones del régimen contractual, ya sea por imposibilidad o impertinencia. De ahí que la tarea del intérprete es dotar a esa relación atípica de ciertos parámetros normativos para resolver los problemas que puedan generarse por incumplimiento, lo que exige clarificar el contenido del contrato médico.

\section{EL CONTENIDO CONTRACTUAL}

El contenido del contrato médico queda determinado hoy por el legislador, mediante la introducción de deberes específicos a cargo de los médicos y, por la obligación de sujetarse a la lex artis. Ambos componentes resultan esenciales para comprender la responsabilidad médica. Los deberes y obligaciones del médico quedan modelados por esas fuentes que integran el contrato por vía directa -voluntad del legislador y del administrador- y, por otra parte, en forma persistente la evolución de la medicina impacta en lo que se estima apropiado como conducta de los médicos, a través de la noción de lex artis. En lo que sigue describiremos esas fuentes del contenido contractual.

\subsection{EL CONTENIDO IMPERATIVO POR OBRA DEL LEGISLADOR}

Un primer aspecto, a propósito de la Ley no 20.584 de 2012 sobre derechos y deberes de los pacientes, es considerar que la normativa introduce un contenido imperativo al contrato médico. La atención de salud, ya sea a través de prestadores privados o públicos, aunque sobre todo en los primeros, aparece con un marcado carácter contractual. La regla general en las prestaciones médicas es la existencia de un vínculo contractual entre el paciente y el prestador médico, sea individual o institucional. La Ley 20.584 de 2012 es clara en su artículo $1^{\circ}$, indicando que sus disposiciones se aplicarán a cualquier tipo de prestador

\footnotetext{
25 Mantilla (2008) pp. 488 y ss.

26 Mantilla (2008) pp. 490 y ss. el autor cuestiona la calificación de contrato tratándose de la relación médicopaciente, pero al mismo tiempo la entiende como una sucesión de contratos, lo que aparece como contradictorio.
} 
público o privado, extendiendo su obligatoriedad a los demás profesionales y trabajadores, sin importar la causa, que los coloque en situación de atender público o se vinculen con el otorgamiento de las atenciones de salud. ¿Qué lectura puede hacerse a las expresiones "prestadores institucionales" y "prestadores privados" a la luz de la responsabilidad civil?

Desentrañar su comprensión desde la responsabilidad civil es bastante sencillo.

Son los posibles legitimados pasivos de las demandas indemnizatorias por incumplimiento de las obligaciones previstas en la ley, pudiendo ser personas jurídicas, en su sentido más amplio o personas naturales.

En el ámbito del contrato médico o, más amplio, tratándose de prestaciones médicas, la seguridad del paciente constituye un elemento de especial interés. Se refiere el artículo 4 de la Ley 20.584 de 2012 a los "protocolos establecidos, en materia de seguridad del paciente y calidad de la atención de salud”. Aquí es interesante referirse a la irrupción de la obligación de seguridad. En el derecho comparado y en Chile, en otros ámbitos, particularmente en relación a los trabajadores, la obligación de seguridad ha tenido una expansión considerable ${ }^{27}$. Si existe una relación contractual se ha entendido en forma más o menos compartida que concurre una obligación de seguridad en todo contrato en que existe un riesgo para la integridad física o síquica del acreedor. Esto a partir de la función de interpretación de la buena fe que se entiende incorporada al contrato ${ }^{28}$.

$\mathrm{Su}$ inclusión en el contenido contractual ha significado una competencia acérrima con su par extracontractual, otorgándole una función indemnizatoria significativa a la responsabilidad contractual, cada vez que se entiende lesionada la seguridad que se debe al paciente. Al existir un contrato, la indemnización que reclama el acreedor por las lesiones ocasionadas consecutivas a la infracción del deber de seguridad, quedan bajo el amparo de la responsabilidad contractual. Sin perjuicio que en esos casos, en la unanimidad, estamos frente a la concurrencia de responsabilidad civil ${ }^{29}$.

En la citada Ley no 20.584 de 2012 se introduce ahora una obligación legal de seguridad a favor del paciente para todo tipo de prestaciones médicas, dejando atrás el fundamento basado en la buena fe. El Párrafo $1^{\circ}$ lleva por título "De la seguridad en la atención de salud", estableciendo en su artículo 4:

"Toda persona tiene derecho a que, en el marco de la atención de salud que se le brinda, los miembros del equipo de salud y los prestadores institucionales cumplan las normas vigentes en el país, y con los protocolos establecidos, en materia de seguridad del paciente y calidad de la atención de salud, referentes a materias tales como infecciones in-

27 Véase, Barros (2006) p. 340. En particular sobre daños y accidentes laborales, Diez (2009) pp. 705 y ss. y Sierra y NASSER (2012) pp. 57 y ss.

${ }^{28}$ BoETsCh (2011) p. 115, quien se explaya sobre la función creadora de especiales deberes de conducta, a partir de la buena fe.

29 Una panorámica reciente, delimitando el problema del concurso, Corral (2010) p. 639. Creemos, en todo caso, que el problema de la concurrencia de responsabilidad civil ha decaído, pues ya no existen motivos relevantes que impulsen al acreedor a preferir la vía extracontractual. Habiéndose aprobado la indemnización del daño moral por incumplimiento de contrato a mediados de los años 90 , solo quedan como diferencias relevantes, la regla de previsibilidad contemplada en el artículo 1558 del Código Civil, cuya aplicación es escasa y poco relevante en materia de daños físicos y la regla de la solidaridad, aplicable solo en el ámbito extracontractual. Podría, por último, considerarse la diferencia en el plazo de prescripción. 
trahospitalarias y, en general, todos aquellos eventos adversos evitables según las prácticas comúnmente aceptadas". Y agrega:

"Las normas y protocolos a que se refiere el inciso primero serán aprobados por resolución del Ministerio de Salud, publicada en el Diario Oficial, y deberán ser permanentemente revisados y actualizados de acuerdo a la evidencia científica disponible". Lo que resulta relevante hoy es que esta norma dio lugar a la dictación de una serie de protocolos médicos para eventos adversos y centinela, estableciendo conductas específicas que deben llevarse a cabo para evitar dichos sucesos aciagos.

Conforme esta disposición, el Ministerio de Salud por Resolución Exenta no 1031 del 17 de octubre de 2012 aprobó protocolos y normas sobre seguridad del paciente y calidad de la atención de salud. Esta Resolución ratifica el carácter amplio de la norma en relación a la seguridad del paciente. Así dispone en su numerando 30: "Que el artículo 4º, de la citada Ley, entrega al Ministerio de Salud la facultad de aprobar normas y protocolos establecidos en materia de seguridad del paciente y calidad de la atención de salud, referente a materias tales como infecciones intrahospitalarias, identificación y accidentalidad de los pacientes, errores en la atención de salud y, en general, todos aquellos eventos adversos evitables según las prácticas comúnmente aceptadas". A partir de esta norma todo el esplendor de la potestad administrativa puede desempeñarse. Es posible advertir que la resolución, en esta parte, se limita a reproducir el artículo 4 que le otorga la competencia al Ministerio para dictarla, pero agrega que en el ámbito de los protocolos de seguridad se incluirán los "errores en la atención de salud", ratificando, además, el carácter ejemplar de la norma, pues se refiere, en general, a los eventos adversos evitables. Conforme la norma se dictaron 9 protocolos que constituyen una reglamentación imperativa para los prestadores de salud. La contravención a los mismos acarrea responsabilidad en el evento que a resultas de la infracción se ocasione un perjuicio al paciente. Si nos encontramos en el ámbito contractual, dichos protocolos forman parte del contenido obligacional.

Un análisis a dichos protocolos nos ilustra ese contenido imperativo en la actual relación médico-paciente.

\subsection{Noción de SEGURIDAd DEL PACIENTE}

En el protocolo no 1 dictado por el Ministerio de Salud se alude a la seguridad del paciente como "un componente fundamental de la atención de salud" y se trata de "un proceso que se centra en el conocimiento de los riesgos de eventos adversos tanto del prestador institucional, prestador individual y del usuario, la eliminación de los innecesarios y la prevención de aquellos que son evitables a través de intervenciones basadas en evidencia científica con demostrada efectividad". La exégesis de este protocolo otorga al deber de seguridad un asiento normativo, que si bien ya estaba en la Ley 20.584 de 2012 que otorgó la remisión normativa al órgano administrativo -Ministerio de Salud-, la complementa, exigiendo al médico un conocimiento relativo a los eventos adversos, impulsándolo a una conducta basada en la previsión y evitabilidad de los mismos. Sin embargo, esta norma es de textura abierta, lo que impide una fácil aplicación. Como primera manifestación, se exige al médico el conocimiento de los riesgos asociados al acto médico, eso permitirá, por cierto, satisfacer el deber de información a favor del paciente. Al conocer los riesgos, 
el médico es compelido no solo a informar, sino a excluir su ocurrencia, para el caso, que dichos riesgos puedan evitarse. La conducta del médico debe orientarse a evitar los riesgos o eventos adversos, lo que no significa que sea responsable por la ocurrencia de los mismos. Lo que se evalúa es si podía prever la ocurrencia del evento adverso y, en ese caso, si pudo haberlo evitado empleando una diligencia que le es exigible. De alguna manera, entonces, la seguridad reenvía al debate acerca de la lex artis exigible al médico.

\subsection{EVENTOS ADVERSOS Y EVENTOS CENTINELA}

En la nomenclatura sanitaria ha cobrado un interés mayor la definición de los eventos adversos y, en menor medida, los eventos centinela. Aquellos se definen en el Protocolo no 1 como "una situación o acontecimiento inesperado, relacionado con la atención sanitaria recibida por el paciente que tiene, o puede tener, consecuencias negativas para el mismo y que no está relacionado con el curso natural de la enfermedad". A su turno, "evento centinela" consiste en "un suceso inesperado que puede producir la muerte o serias secuelas físicas o psicológicas, o el riesgo potencial de que esto ocurra".

En ambos casos se trata de un acontecimiento "inesperado", es decir, no estaba en las previsiones de la intervención o atención médica que ocurriera. Ocurre sin que haya sido esperado. Tratándose del "evento adverso" no es consubstancial que ocasione un daño al paciente, puede ocurrir, pero no en forma necesaria. Además, está conectado con el acto médico y es ajeno a lo que debiera ser el desarrollo ordinario de la enfermedad. Por su parte, el "evento centinela", si bien también es inesperado, sus consecuencias son, sí o sí, más graves, al poder ocasionar la muerte o serias secuelas físicas o sicológicas. He ahí la diferencia más relevante entre ambos conceptos. Si bien, la regulación de estos eventos es meticulosa en torno al procedimiento que debe seguirse si ocurren, mediante un protocolo estricto de información, registro y manejo de los mismos; no existe, lo que es lógico, un planteamiento acerca de su relación con la posible responsabilidad civil de quien ha participado en la generación del suceso.

En todo caso, se asume que "algunos eventos cuentan con prácticas clínicas de evidencia demostrada para su prevención y ante la ocurrencia de alguno se debe revisar el cumplimiento de estas normas de prevención”. Esto nos ratifica que la ocurrencia del evento adverso o centinela puede haberse originado por negligencia en las prácticas de prevención. Si bien en el lenguaje de la responsabilidad civil es un tanto contradictorio referirse a estos eventos como "inesperados" y, luego, aludir a la existencia de prácticas que permiten "preverlos", debemos entender esta aparente contradicción en el sentido que lo normal es que no se verifiquen, pero que concurre la exigencia de prevenirlo apegándose a las prácticas clínicas exigibles a los médicos y demás prestadores de salud. De ahí que el mismo Protocolo no 2 señale "Si se verifica la ausencia de aplicación de las medidas de prevención establecidas y el profesional no justificó su acción, se procederá (1) reportar el caso a la Dirección Médica para las medidas técnico administrativas que considere pertinentes y (2) a realizar una investigación inmediata destinada a proteger la seguridad de los otros pacientes".

Lo importante es que se hace referencia a determinadas prácticas clínicas, que es lo que dota de contenido a la lex artis de los médicos, conforme se analizará más tarde. Incluso, si se detectó un evento adverso o centinela, la investigación para ratificarlo o excluir la 
calificación, constituye un informe o documento importante a considerar en los eventuales juicios. Existe ahí una opinión profesional que se pronuncia sobre el apego o infracción a dichas prácticas clínicas.

En todo caso, los eventos adversos no son sinónimos de responsabilidad. Y el protocolo se concentra en mostrar un procedimiento a ejecutar para el caso que se detecte un evento adverso o centinela. En ningún caso cabe concluir que el acaecimiento involucra una responsabilidad civil. Tratándose de medicina hay una serie de consecuencias adversas que los pacientes pueden padecer, sin que haya negligencia alguna que imputar. Son genuinos accidentes médicos, cuya ocurrencia puede intentar prevenirse o aminorarse, pero que suelen ocurrir con alguna estadística almacenada por la administración sanitaria. Es difícil, por otra parte, saber cuántos eventos adversos o centinela ocurren sin que se haya ejecutado el procedimiento de prevención previsto en el protocolo $\mathrm{n}^{\circ} 2$. Ese marcado carácter preventivo que inspira la normativa queda reflejado en las "recomendaciones para su aplicación: La creación de un sistema de reporte de problemas de seguridad en la atención con frecuencia constituye una estrategia para aprender de los errores y evitar su ocurrencia en el contexto de mejora continua”.

En anexo $n^{\circ} 1$ se detallan conductas en relación a específicos "eventos centinela". Tratándose de la seguridad en cirugía se mencionan los siguientes eventos centinela y las medidas que deben ser supervisadas.

La enfermedad tromboembólica -ETE- en pacientes quirúrgicos (trombosis venosa profunda o tromboembolismo pulmonar). Se deben seguir las normas y protocolos de prevención de ETE en todos los pacientes quirúrgicos de riesgo. Se exige, además, evaluar de riesgo ETE al paciente específico. A todo paciente en riesgo corresponde aplicarle las medidas de prevención. Y, por último, el protocolo de manejo clínico de la ETE.

La cirugía de paciente equivocado debe prevenirse con la aplicación de la lista de chequeo en todos los pacientes operados, las normas de identificación del paciente y el procedimiento de identificación aplicado en el caso centinela. Algo similar ocurre con la cirugía en sitio errado. Se aplica la lista de chequeo en todos los pacientes operados y aquel de marcación del sitio quirúrgico en el caso centinela. Las listas de chequeo consisten en un instrumento mnemotécnico o recordatorio activo. Y, cabría agregar, que las listas de chequeo en el caso de la cirugía están a cargo del primer cirujano.

Para el evento de cuerpo extraño olvidado, se prevé la aplicación de la lista de chequeo en todos los pacientes operados y el recuento de compresas e instrumental. En los paros cardiacos intraoperatorios, se procede a la aplicación de la lista de chequeo en todos los pacientes operados y protocolos de evaluación preanestésica en el caso centinela. Por último, a propósito de la extirpación no programada de un órgano, se aplica la lista de chequeo en todos los pacientes operados.

Y así, en forma detallada, se establecen medidas imperativas para el ámbito de infecciones asociadas a la atención de salud en caso de prolongación o reaparición de brote epidémico o distribución de material no estéril a los servicios clínicos; atención obstetricia, por muerte materna, muerte fetal tardía o asfixia neonatal; seguridad en la medicina transfuncional, ya sea por transfusión a paciente equivocado o de componentes sanguíneos sin tamizajes microbiológicos conformes, infección por un agente transmisible que no se puede 
transmitir por transfusiones, reacción hemolítica aguda por incompatibilidad de grupo sanguíneo, reacción sobre carga de volumen y, por último, como ámbito de aplicación la atención y cuidados de los pacientes. Ya sea por caída de pacientes con o sin daño severo, debiendo aplicarse el cumplimiento de medidas locales de prevención de caídas; úlceras por presión y extravío de biopsias.

Este marco general da paso en los protocolos siguientes a especificar las conductas requeridas a los prestadores de salud en cada ámbito ya descrito. El no 3 relativo a "Normas sobre seguridad del paciente y calidad respecto de: aplicación de lista de chequeo para la seguridad de la cirugía"; no 4 "Normas sobre seguridad del paciente y calidad de la atención respecto de: análisis de reoperaciones quirúrgicas no programadas"; no 5 "Normas sobre seguridad del paciente y calidad de la atención respecto de: prevención enfermedad tromboembólica en pacientes quirúrgicos"; no 6 "Normas sobre seguridad del paciente y calidad de la atención respecto de: prevención úlceras o lesiones por presión (UPP) en pacientes hospitalizados"; no 7 "Normas sobre la seguridad de la atención del paciente y calidad de la atención respecto de: reporte de caídas de pacientes hospitalizados"; no 8 "Normas sobre seguridad del paciente y calidad de la atención respecto de: pacientes transfundidos de acuerdo a protocolo" y, por último "Normas de los programas de prevención y control de las infecciones asociadas a la atención de salud".

Es posible concluir que a partir de la Ley 20.585 de 2012 se ha extendido el deber de seguridad, cuyo contenido se refleja en una serie de prácticas clínicas y protocolos que debemos considerar imperativos para los prestadores de la salud, incluidos los médicos. Sin embargo, ese contenido imperativo no excluye, sino que constituye una porción de lo que les resulta obligatorio a los médicos. La otra parte de ese contenido contractual está modelada por la lex artis.

\subsection{LEX ARTIS: LA CONDUCTA ESPERADA DE LOS MÉDICOS}

El contenido contractual, todavía y en mayor medida, queda entregado a la lex artis médica. En el ámbito de la responsabilidad profesional, los médicos están sometidos a respetar sus reglas del oficio. El problema consiste en determinar cuáles son las conductas pertinentes para cada caso específico. La disconformidad de la conducta del médico con su lex artis deberá calificarse como culpa. En consecuencia, fuera del contenido determinado por el legislador, los médicos pueden quedar expuestos a responsabilidad por no comportarse como lo haría un buen médico. La lex artis constituye el patrón de conducta que les resulta exigible, aunque no esté prevista la conducta en forma expresa en la ley. Entonces esta sería una segunda fuente de deberes y obligaciones que es usual que se vaya construyendo a través de la jurisprudencia. Si un médico incumple deberes propios a su profesión construidos a partir de un modelo de comportamiento deberá indemnizar los daños ocasionados. Así la define la Corte Suprema:

"La legis artis ha emergido como el referente o módulo de comparación para determinar la existencia de la vinculación normativa, tipicidad u obligación a la cual debe responder el médico al desempeñar su profesión. Como módulo de comparación, tiene su explicación en el hecho que la responsabilidad se genera por el incumpli- 
miento de las obligaciones que redunda en un resultado dañoso y, en el evento que se estime que ese daño no es producto de un actuar reprochable, debe establecerse que la actuación se ajustó a la lex artis; $13^{\circ}$ ) Que las acciones de salud corresponde sean desarrolladas conforme a la Lex Artis Médica, que constituye el parámetro de comparación de la actividad desplegada por los médicos, caracterizada como una obligación de previsión, asistencia, diligencia, cuidado y garantía del respectivo facultativo. A lo anterior se añade, como patrón de comparación, que dicha prestación se realice en los términos exigidos para un profesional médico promedio, que se eleva cuando se está ante un especialista, puesto que en este caso se evalúa como un especialista promedio. En todas las acciones de salud en que toma parte, su conducta se valora desde un punto de vista de un profesional o especialista prudente, diligente, perito en su especialidad y que actúa observando los reglamentos que le son exigibles, teniendo presente las circunstancias del caso, especialmente de tiempo y lugar. La valoración en abstracto de la culpabilidad se encamina a una variable con ribetes concretos, con lo cual se las conjuga para obtener una decisión más justa" ${ }^{30}$.

En el mismo sentido, reproduciendo un considerando usual en los casos de responsabilidad médica, la Corte Suprema sostuvo:

"[E]n el ejercicio del acto médico, el profesional se obliga a emplear todos sus conocimientos y medios suficientes y disponibles con el objetivo de precaver, diagnosticar, tratar y curar la enfermedad" 31 .

Asumido en forma abstracta qué debe entenderse por lex artis, queda una interrogante relevante acerca del contenido de la misma. ¿Cómo construir aquellas conductas que le son exigibles a los médicos conforme a su oficio? Desde antiguo se ha aludido a los usos propios al arte médico. Esas prácticas que en forma paulatina y consistente van repitiéndose en el tiempo. La costumbre, entonces, es una fuente relevante para definir la lex artis. Aquello que resulta usual y consuetudinario para los médicos pasa a serles exigible. Sin embargo, hoy por hoy, la medicina va más allá de la simple costumbre. Son los protocolos o descripciones de cómo debe comportarse el médico, conforme la ciencia médica, lo que permite dotar de contenido a la lex artis.

La Corte de apelaciones de Concepción ha fallado:

"Que, establecido el marco general de responsabilidad por imputación del médico, cuando, si no se han especificado las obligaciones del servicio prestado, el contenido general de una obligación contractual de medios es equivalente a los deberes de prudencia y diligencia que debe observar el médico, de acuerdo a sus conocimientos y especialidad en el desempeñó de atención al enfermo, conforme a los estándares de cuidado requeridos para adoptar todas las medidas tendientes a la recuperación

\footnotetext{
30 Wagemann con Vidal (2011).
}

31 Treizman con Reyes (2013). 
del estado de salud y evitar el daño colateral, conforme a los protocolos y lex artis correspondiente a su ciencia, pero no se puede obligarlo a obtener, necesariamente y siempre, el resultado deseado, pues depende de múltiples condicionantes, muchas veces ajenas a la voluntad del tratante" 32 .

Enseguida, la Corte concluye que:

“...en la especie, con la prueba rendida en autos y que se refiere en los considerandos $7^{\circ}$ y $8^{\circ}$ del fallo que se reproduce, en especial, la documental, consistente en la ficha clínica, TAC cerebral, exámenes clínicos y testimonial de los médicos especialistas, apreciadas en conformidad a la ley, se estableció, que el actor ingresó al Sanatorio Alemán con compromiso de conciencia y con antecedentes de enfermedad de Crohn, siendo atendido en urgencia por varios médicos, se le practica un TAC de cerebro, sugerente de principio de infarto cerebral con compromiso expansivo, edema, se ordenan exámenes, se plantea cirugía cerebral, la que fue bien tolerada, extrayéndose parte de un "tumor", al que se le practica biopsia rápida. Este procedimiento fue estimado como el adecuado por los médicos señor Francisco Mucientes Herrera y señora Elizabeth Daube Krisan, según declaración prestada en el juicio"33.

De esta manera se deja de lado cualquier reproche a la conducta de los médicos, la que se estimó satisfizo la lex artis que les era exigible.

Puede observarse que el contenido de la relación médico-paciente, entendida como un contrato atípico y complejo, se construye en cuanto a su contenido a través de los protocolos definidos por la postestad reglamentaria y, por cierto, en la forma en que para el caso específico debe entenderse la lex artis aplicable.

Una vez que hemos determinado el contenido contractual de la relación médicopaciente, parece necesario referirse a cuáles podrían ser las consecuencias de su infracción o, en términos de responsabilidad contractual, del incumplimiento.

\section{LA RESPONSABILIDAD POR INCUMPLIMIENTO DEL CONTRATO MÉDICO}

El interés que muestra definir el contenido contractual y, en particular, aquellas obligaciones y deberes que emanan de la voluntad del legislador y la lex artis, es la responsabilidad que se deriva para el médico. A estas alturas uno de los asuntos más discutidos por la doctrina nacional, en el ámbito del derecho de las obligaciones, ha sido la conveniencia o no de aceptar la clasificación entre las obligaciones de medios y aquellas de resultado y, para quienes la estimamos necesaria, cuáles serían sus respectivos efectos. Sin pretender recoger

32 Sin registrar con Corporación (2012).

33 Sin registrar con Corporación (2012). 
aquí todo el debate dogmático, solo aludiré a algunas cuestiones esenciales para determinar el régimen de responsabilidad aplicable ${ }^{34}$.

Entender la obligación del médico como una de medios o de resultado no es inocuo, pues determina si nos encontramos frente a una hipótesis de responsabilidad por culpa $\mathrm{u}$ objetiva. Al considerarla una obligación de medios solo debemos determinar si se desplegó en forma adecuada la conducta conducente a resguardar la seguridad del paciente, conforme a un estándar de conducta previsto en la ley o el reglamento o la lex artis del prestador. Si hay un desajuste entre el actuar y lo que se espera deba ejecutar, habrá culpa y, por ende, si hubiere daño, se desencadena la responsabilidad. Aún más, hemos propuesto que, al igual que en todas las obligaciones contractuales, el acreedor, en este caso el paciente, debe acreditar la relación médico-paciente y alegar el incumplimiento, siendo el médico -deudor-, quien conforme al artículo 1547 inciso $3^{\circ}$ del Código Civil debe desplegar el esfuerzo probatorio para acreditar que se ajustó a la lex artis o que cumplió el deber imperativo del legislador. Esto es concordante con el artículo 1698 del Código Civil que exige la prueba de la extinción de la obligación a quien la alega ${ }^{35}$. En otros términos, solo le correspondería al paciente aportar los elementos de prueba necesarios para corroborar la existencia del contrato y, en particular, la obligación médica. Resorte del médico será corroborar que ejecutó la conducta que le era exigible ${ }^{36}$. Debemos entender, además, que si el médico cumple con aportar los medios probatorios que justifican su conducta conforme a lo esperado, en ese caso, lo que acredita es el pago de su obligación o, lo que es lo mismo, la satisfacción óptima del paciente, con independencia que haya ocasionado un daño.

En este sentido lo afirma la Corte de apelaciones de Santiago en un reciente fallo:

"Que para la procedencia de dicha acción, la parte demandante debe probar la existencia de la obligación y afirmar el incumplimiento en que incurrió el demandado, para obligar a éste a acreditar la diligencia con que actuó o la exclusión de su responsabilidad por causa legal. Lo anterior, atendido lo dispuesto en el artículo 1547 inciso tercero del Código Civil y el hecho de tratarse en la especie de una obligación de medios" 37 .

La Corte concluyó que el médico aportó las pruebas necesarias para dar por satisfecha su obligación. Así lo afirmó:

\footnotetext{
34 Sobre esta cuestión, en materia médica, véase CÁrdenas (2010) p. 45. En términos amplios, PeñaIlillo (2003) pp. 338 y ss.; Barros (2006) p. 662; Tapia (2003) p. 75; Pizarro (2008b) p. 255; Domínguez Hidalgo (2010) pp. 21 y ss.

35 Pizarro (2008b) pp. 255 y ss. Sobre los mismo, Domínguez (2008) pp. 122 y ss.

36 Cfr. Barros (2006) p. 680; CÁrdenas (2010) pp. 45 y ss. Mientras el primero entiende que las obligaciones de los médicos son de medios, pero sin que se les aplique la presunción de culpa del artículo 1547 inciso $3^{\circ}$ del Código Civil; el segundo, entiende dicho precepto aplicable solo a las obligaciones de dar una especie o cuerpo cierto. Siguiendo en términos explícitos la tesis de Barros, véase Sin registrar con Corporación (2012).

37 Durson con Basauri (2013).
} 
"El mérito probatorio de las pericias médicas en cuestión conducen inequívocamente a concluir que el médico demandado se desempeñó conforme a las reglas propias de su lex artis, con la debida diligencia" 38 .

En otro caso la Corte Suprema falló:

"Con todo, aunque lo recién señalado permita entrever el destino del esfuerzo sanador, la Corte no eludirá una mirada sobre el fondo de la alegación y, al efecto, con buena voluntad extrae del escrito que la conduce, la única parte que pudiera ser tenida como explicación de uno de los defectos que se imputa a la sentencia, en la que se expresa, a la letra: "En cuanto a la afirmación del sentenciador de segunda instancia, corresponde al médico y hospital que observaron la debida diligencia o cuidado, como lo prescribe el inciso tercero, del artículo 1547, del Código Civil y no el actor, como se ha resuelto el fallo recurrido" 39 .

En este caso, la Corte no solo estimó que no había reproche alguno para los médicos, sino que tampoco se verificaba el vínculo causal entre la muerte y un supuesto incumplimiento.

De ahí que la carga probatoria de la diligencia y, al mismo tiempo, del cumplimiento fue satisfecha por el médico, resultando aplicable, tanto el artículo 1547 inciso $3^{\circ}$ como el 1698, ambos del Código Civil. Frente a la incertidumbre acerca de si el médico satisfizo o no el estándar de conducta esperable, le perjudica, al no haber acreditado, conforme el artículo 1698 del Código Civil, la extinción de la obligación.

En cambio, si uno avanza a calificar la obligación médica como una de resultado, debiera considerarse que la responsabilidad es objetiva. No es necesario un comportamiento inadecuado o desajustado, solo se requiere, para que haya responsabilidad, que se verifique la infracción a la obligación y el daño. No es el comportamiento lo que se analiza, sino que basta el acto y el daño para que exista responsabilidad ${ }^{40}$. En otros términos no existe una presunción de culpa, sino que el hecho u omisión del médico que causa daño es suficiente para establecer la responsabilidad.

Es cierto que la jurisprudencia nacional, al menos en términos explícitos, no ha avanzado a introducir una responsabilidad objetiva en el ámbito contractual, pero ya en un fallo de la Corte Suprema, a propósito de una intervención de cirugía estética calificó la obligación como de resultado, restringiendo las vías de exoneración de responsabilidad para el médico. La Suprema falló:

"Que el demandado [médico], precisamente en lo que constituía su obligación, no ha rendido prueba suficiente, pues siempre estimó que, limitando su responsabilidad, solo debía acreditar haber cumplido su cometido sujetándose a las normas de la

\footnotetext{
38 Durson con Basauri (2013).

39 Delgado con Pontificia Universidad Católica de Chile (2012).

40 Peñailillo (2009) pp. 488 y ss.
} 
lex artis de la ciencia médica, restringiendo a ese punto el cumplimiento del contrato sin rendir prueba a cerca del resultado prometido, esto es, lo que precisamente motivaba a contratar a la demandante, es decir, el hermoseamiento, embellecimiento o mejora estética de aquella" ${ }^{41}$.

De ahí que la distribución del riesgo sea diversa en contraste con las obligaciones de medios $^{42}$. Solo en la hipótesis de fuerza mayor u otra causa extraña, el deudor podrá liberarse, siendo irrelevante la diligencia como excusa. Si bien la calificación de la obligación médica como de resultado es excepcional, pues sigue siendo un oficio marcado por el aleas del resultado, aquellas deben calificarse como tales a partir de una interpretación del contenido contractual en el contexto del propósito práctico perseguido por la convención, a lo que debe agregarse considerar los usos y la lex artis médica integrada en el contrato.

Si asumimos la pertinencia de la distinción entre obligaciones de medios y de resultado, estamos modelando al mismo tiempo el régimen de responsabilidad por incumplimiento. Por lo mismo, es posible sostener que a propósito de la indemnización de perjuicios o, más amplio, en el ámbito de la responsabilidad contractual, conviven dos regímenes, aquel en que la culpa sí constituye el fundamento de la responsabilidad conforme el artículo 1547 del Código Civil y las otras, cuyo fundamento debe encontrarse en el artículo 1556 del Código Civil en que la diligencia no es integradora de la noción de cumplimiento, sino tan solo promotora del mismo, lo que la hace irrelevante a la hora de definir la ejecución y las consecuencias del incumplimiento ${ }^{43}$.

\section{CONCLUSIÓN}

Hemos querido en este trabajo mostrar los nuevos contornos de la relación médicopaciente, la que debe calificarse como un contrato de servicios o prestación de servicios médicos, que es atípico y complejo. Debe excluirse la calificación de mandato, por impertinente desde una perspectiva normativa, práctica e histórica.

El contenido del contrato médico ha pasado a ser marcadamente dirigido, a través de la potestad administrativa que, impulsada por el legislador, ha ido estableciendo ingentes conductas obligatorias para los médicos que se plasman en protocolos y prácticas clínicas. Aparte este contenido imperativo, la lex artis sigue siendo la fuente principal de deberes médicos, la que se determina conforme los avances de la medicina y las circunstancias en que se ejecuta el acto médico.

Una vez modelado el contenido del contrato médico, la responsabilidad por infracción del profesional, queda definida conforme se califique la obligación como una de medios o de resultado. Mientras la primera, que constituye el régimen general, amerita un régimen por culpa presunta conforme el artículo 1547 inciso $3^{\circ}$ del Código Civil; las de

\footnotetext{
41 Cortés con García (2011).

42 Díez Picazo (2008) p. 282.

43 Peñailillo (2003) pp. 342 y 343.
} 
resultado abren el escenario médico para la responsabilidad objetiva, reduciendo las excusas del médico solo a la causa extraña o fuerza mayor.

\section{BIBLIOGRAFÍA CITADA}

Alessandri Rodríguez, Arturo (1940): "El contrato dirigido", Revista de Derecho y Jurisprudencia, t. XXXVIII: pp. 5 y ss.

Alessandri Rodríguez, Arturo (1943): De la responsabilidad extracontractual en el derecho civil chileno (Santiago, Editorial Universitaria).

Barros bourie, Enrique (2006): Tratado de Responsabilidad Extracontractual (Santiago, Editorial Jurídica de Chile).

Boetsch Gillet, Cristián (2011) La buena fe contractual (Santiago, Editorial Jurídica de Chile).

CÁrdenas Villlarreal, Hugo (2010a): "La cobertura dogmática de la recepción jurisprudencial de la distinción obligaciones de medios/obligaciones de resultado (una aproximación a través de casos de responsabilidad médica)”, en DE LA MAZA, Iñigo (edit.), Cuadernos de Análisis Jurídico. Colección Derecho Privado. Temas de Responsabilidad Médica (Santiago, Fundación Fernando Fueyo Laneri) pp. 45-84.

Cárdenas Villlarreal, Hugo (2010b): "La acción de repetición del Fisco en contra del personal médico-sanitario", en Estudios de Derecho Civil V (Santiago, Abeledo-Perrot) pp. 527-541.

Cárdenas Villlarreal, Hugo y Moreno Mollinet, Jaime (2011): Responsabilidad médica. Estándares jurisprudenciales de la falta de servicio (Santiago, Thompson-Reuters).

Corral Talciani, Hernán (2003): Lecciones de responsabilidad extracontractual (Santiago, Editorial Jurídica de Chile).

Corral Talciani, Hernán (2010): "El concurso de responsabilidades en el derecho de daños chileno: defensa y delimitación de la teoría de la opción”, en Estudios de Derecho Civil V(Santiago, Abeledo-Perrot) pp. 639-653.

De la Maza Rivadeneira, Lorenzo (1989): "El contrato de atención médica”, Revista de Derecho, vol. 16: pp. 7 y ss.

Díez Picazo, Luis (2008): Fundamentos de derecho civil patrimonial. Las relaciones obligatorias (Madrid, Thompson-Civitas).

Domínguez Águila, Ramón (2008) "La culpa en el derecho civil chileno. Aspectos generales”, Revista Anales Derecho UC, No 3: pp. 107-138.

Domínguez Hidalgo, Carmen (2010): "El problema de la culpa presunta contractual y las obligaciones de medio y obligaciones de resultado: sus implicancias para la responsabilidad médica", en De la Maza Gazmuri, Iñigo (compilador), Cuadernos de análisis jurídico. Colección Derecho Privado (Santiago, Ediciones Universidad Diego Portales) pp. 21-44.

Domínguez Hidalgo, Carmen (2006): "Naturaleza y fundamento de la responsabilidad civil del profesional liberal”, Revista Anales Derecho UC, No 1: p. 121-141.

Domínguez Hidalgo, Carmen (2011): "Aspectos de la integración del contrato", en Estudios de Derecho Civil VI (Santiago, LegalPublishing) pp. 251-262.

Figueroa García-Huidobro, Rodolfo (2010): "Autonomía de los pacientes y responsabilidad de los médicos”, en De la maza Gazmuri, Iñigo (compilador), Cuadernos de análisis 
jurídico. Colección Derecho Privado (Santiago, Ediciones Universidad Diego Portales) pp. 199-221.

GuZMÁn Brito, Alejandro et al. (2005): De la codificación a la descodificación (Santiago, Fundación Fernando Fueyo Laneri).

LeVI, Jean Philippe y Castaldo, André (2002): Histoire du droit civil (Paris, Dalloz).

López Santa-María, Jorge (2010): Los Contratos. Parte General (Santiago, Editorial Jurídica de Chile).

Mantilla Espinosa, Fabricio (2008): "El contrato de prestación de servicios médicos en el derecho colombiano" Colección de estudios de derecho civil en homenaje a la profesora Inés Pardo de Carvallo (Valparaíso, Ediciones Universitarias de Valparaíso) pp. 483-504.

Momberg Uribe, Rodrigo (2013): "Comentario artículo 2 bis Ley 19.496" en De la Maza, Iñigo; Pizarro, Carlos (Directores) La protección de los derechos de los consumidores (Santiago, Thompson-LegalPublishing) pp. 75 y ss.

Peñailillo Arévalo, Daniel (2003): Obligaciones. Teoría general y clasificaciones. La resolución por incumplimiento (Santiago, Editorial Jurídica de Chile).

Peñailillo Arévalo, Daniel (2009): "Responsabilidad contractual objetiva”, en Pizarro, Carlos (coordinador), Estudios de Derecho Civil, IV (Santiago, LexisNexis) pp. 488-501.

Pizarro Wilson, Carlos (2003): "La responsabilidad médica por el hecho ajeno", Revista Chilena de Derecho Privado no 1: pp. 181-205.

Pizarro Wilson, Carlos (2007): "La responsabilidad civil de los hospitales públicos. La ley del auge en perspectiva civil”, Estudios de Derecho Civil, t. II (Santiago, LexisNexis) pp. 401-420.

Pizarro Wilson, Carlos (2008a): "Responsabilidad profesional médica: Diagnóstico y perspectivas” en Revista Médica de Chile, V. 136, no 4: pp. 539-543.

Pizarro Wilson, Carlos (2008b): "La culpa como elemento constitutivo del incumplimiento en las obligaciones de medio o de diligencia", Revista de Derecho de la Pontificia Universidad Católica de Valparaíso, XXXI: pp. 255-265.

Pizarro Wilson, Carlos (2010): "Controversias jurisprudenciales de la responsabilidad de los servicios públicos de salud", en De la Maza Gazmuri, Iñigo (compilador), Cuadernos de análisis jurídico. Colección Derecho Privado (Santiago, Ediciones Universidad Diego Portales) pp. 187-198.

Pizarro Wilson, Carlos (2011): "Mal praxis en el equipo médico", Revista Médica de Chile, vol. 139, no 3: pp. 668-672.

Sierra Herrero, Alfredo y Nasser Olea, Marcelo (2012): "La responsabilidad del empleador por enfermedades profesionales de sus trabajadores: enfoque jurisprudencial”, Revista Chilena de Derecho vol. 39, no 1: pp. 57-76.

Stitchkin Branover, David (1975): El mandato (Santiago, Editorial Jurídica de Chile).

Tapia Rodríguez, Mauricio (2003): "Responsabilidad Civil Médica: riesgo terapéutico, perjuicio de nacer y otros problemas actuales", Revista de Derecho de Valdivia, Vol. XV: pp. 75-111.

Tocornal Cooper, Josefina (2010): "responsabilidad civil por infecciones intrahospitalarias", Revista Chilena de Derecho, vol. 37, no 4: pp. 477-504. 


\section{NORMAS CITADAS}

Ley no 19.496 del 7 de junio de 1996 "Sobre protección de derechos de los consumidores"

Ley no 19.966 del 3 de septiembre de 2004 "Régimen de garantías en salud" o, más conocida como "Ley Auge".

Ley no 20.584 del 24 de abril de 2012 "Los derechos y deberes que tienen las personas en relación con acciones vinculadas a su atención de salud".

Resolución Exenta no 1031 del 17 de octubre de 2012 del Ministerio de Salud.

\section{JURISPRUDENCIA CITADA}

CORTE SUPREMA

Treizman con Erazo (2013): Corte Suprema, 5 de junio de 2013, Rol 5883-2012, cita online CL/JUR/1219/2013.

Gaete con Integramédica (2007): Corte Suprema, 23 de octubre de 2007, Rol 3667-2007, cita online MJJ15885.

Wagemann con Vidal (2011): Corte Suprema, 28 de enero de 2011, Rol 5849-2009, cita online MJJ26226.

Haydée con Pontificia Universidad Católica de Chile (2012): Corte Suprema, 13 de agosto de 2012, cita online CL/JUR/1698/2012.

Corte de apelaciones de San Miguel

Saccan con Ortega (1992): Corte de apelaciones de San Miguel, 15 de abril de 1992, Gaceta Jurídica, no 143,1992, p. 75-79.

CORTE DE APELACIONES DE CONCEPCIÓN

Sin registrar con Corporación Sanatorio Alemán S.A. (2012): Corte de apelaciones de Concepción, 19 de julio de 2012, cita online CL/JUR/1371/2012.

Corte de apelaciones de Santiago

Durson con Basauri (2013): Corte de apelaciones de Santiago, 15 de octubre de 2013, cita online CL/JUR/2280/2013. 
